\title{
Hematologic Markers as a Predictive Factor for Moderate to Severe Obstructive Sleep Apnea Syndrome in Children and Adolescents
}

\author{
Seung Soo Kim ${ }^{1,2}$, Kwang Ik Yang ${ }^{1,3}$ \\ ${ }^{1}$ Sleep Disorders Center, ${ }^{2}$ Departments of Pediatrics, and ${ }^{3}$ Neurology, Soonchunhyang University Cheonan Hospital, \\ Soonchunhyang University College of Medicine, Cheonan, Korea \\ 소아청소년의 중등도/중증 폐쇄수면무호흡증후군의 예측인자로서 혈액 표지자 \\ 김승수 ${ }^{1,2}$, 양광익 1,3 \\ 순천향대학교 의과대학 천안병원 수면장애센터, ${ }^{1}$ 소아과학교실, ${ }^{2}$ 신경과학교실 ${ }^{3}$
}

$\begin{array}{ll}\text { Received } & \text { May 31, 2018 } \\ \text { Revised } & \text { June 12, 2018 } \\ \text { Accepted } & \text { June 19, 2018 }\end{array}$

Address for correspondence Kwang Ik Yang, MD, PhD

Sleep Disorders Center,

Department of Neurology,

Soonchunhyang University

Cheonan Hospital,

31 Suncheonhyang 6-gil,

Dongnam-gu, Cheonan 31151 ,

Korea

Tel: +82-41-570-2290

Fax: +82-41-592-3810

E-mail: neurofan@schmc.ac.kr
Objectives: We conducted this study to evaluate the diagnostic value of hematologic markers for moderate to severe obstructive sleep apnea syndrome (OSAS). Methods: We performed the study using medical records from our sleep disorders center. We collected information regarding obstructive apnea-hypopnea index (oAHI), age, sex, body mass index, and complete blood counts with differential counts [white blood cell (WBC) count, neutrophil count, lymphocyte count, red blood cell distribution width (RDW), mean platelet volume, platelet count, platelet distribution width (PDW), neutrophil-lymphocyte ratio, and platelet-lymphocyte ratio]. We excluded patients who were younger than 2 years, older than 14 years, obese/underweight, and those who had a hematologic or severe medical illness. Results: We assessed records from 57 patients ( $7.98 \pm 3.25$ years old, 35 men). We classified the subjects into three groups based on their oAHI scores, as follows: normal $(\mathrm{oAHI}<1)$, mild OSAS $(1 \leq \mathrm{oAHI}<5)$, and moderate/severe OSAS (oAHI $\geq 5)$. Using a multivariate multinomial logistic regression model (pseudo $\mathrm{R}^{2}=0.33$ ), we found significant differences among the groups in RDW [moderate/severe OSAS vs. mild OSAS, adjusted odds ratio (OR): 8.77 , $p$-value: 0.03], PDW (mild OSAS vs. normal, adjusted OR: 1.05, $p$-value: 0.04 ), and WBC (moderate/severe OSAS vs. normal, adjusted OR: 1.42, p-value: 0.03). Conclusions: RDW, PDW, and WBC had diagnostic value for moderate/severe OSAS in our study. Further prospective and validation studies are required to develop a screening tool for moderate/severe OSAS in children and adolescents.

J Sleep Med 2018;15(1):20-26

Key Words: Children, Sleep apnea syndrome, Red cell distribution width, Platelet distribution width.

\section{서 론}

소아청소년기의 폐쇄수면무호흡증후군(obstructive sleep apnea syndrome, OSAS)은 성장 및 발달의 지장을 초래하 며, 성인기 건강에까지 영향을 미칠 수 있다. ${ }^{1}$ 성인과 같이 소 아청소년에서도 OSAS를 진단하기 위한 가장 정확한 방법은 야간 수면다원검사(polysomnography, PSG)이다.,2 하지만

This is an Open Access article distributed under the terms of the Creative Commons Attribution Non-Commercial License (https://creativecommons.org/licenses/by-nc/4.0) which permits unrestricted non-commercial use, distribution, and reproduction in any medium, provided the original work is properly cited.
$\mathrm{PSG}$ 는 검사 및 판독에 숙련된 인력이 필요하고, 제한된 기관 에서만 이용 가능하기 때문에 선별검사의 목적으로 다수의 환자에게 적용하기에는 어려움이 있다. ${ }^{2}$ 이에 많은 연구자들 이 수면무호흡증의 선별 진단을 위해 설문지, 산소포화도 점 수 및 소변 생물표지자(biomarker) 등의 검사에 대해 연구하 여 왔다. ${ }^{2-7}$ 하지만 이 중에 소아청소년기 OSAS의 선별검사 로서의 실용적인 가치를 인정받고 널리 쓰이고 있는 검사는 아직 없다. 성인에서는 최근 비교적 쉽게 측정할 수 있는 전체 혈구계산(complete blood count, $\mathrm{CBC)}$ 의 평균혈소판용적 (mean platelet volume, MPV), 적혈구크기분포폭(red blood 
cell distribution width, RDW), 중성구/림프구 비(neutrophil/lymphocyte ratio, NLR), 혈소판/림프구 비(platelet/ lymphocyte ratio, PLR)와 같은 혈액 표지자들(hematologic markers)을 이용한 OSAS의 진단에 대해 많은 연구 보고들이 있었다..$^{-16}$ 하지만 아직까지 소아청소년에서는 이러한 OSAS 에서 혈액 표지자가 갖는 진단적 가치에 대해서 연구가 많지 않은 실정이다. ${ }^{17,18}$ 본 저자들은 단일 기관 수면장애센터의 의무기록을 바탕으로 한 후향적 단면 연구를 통해, 정상 체 중 소아청소년들의 중등도/중증 OSAS의 진단에 있어서 혈 액 표지자가 가지는 유용성을 살펴보고, 추후 전향적 연구 및 대규모 연구를 위한 토대를 마련하고자 이 연구를 수행하 였다.

\section{방 법}

\section{대 상}

2011년 9월부터 2018년 3월까지 본원 수면장애센터에서 수면다원검사를 받은 환자 중 2세 이상 15 세 미만의 소아청 소년을 대상으로 했다. $\mathrm{CBC}$ 검사를 하지 않았거나 검사에 영향을 줄 수 있는 혈액학적 질환 및 심각한 만성 질환이 있 는 경우, 비만 또는 저성장(underweight)아인 경우는 연구 대 상에서 제외했다. 본 연구는 순천향대학교 천안병원 임상시 험심사위원회의 승인을 받았다(SCHCA 2018-05-040-001).

\section{인구통계학적 특성}

환자들의 의무기록을 바탕으로 성별과 수면다원검사 당시 의 연령, 키와 체중을 조사하였다. 신장과 체중을 이용하여 체질량지수(body mass index, BMI)를 구하고 2017년 한국소 아청소년 성장도표의 LMS 값을 이용하여 각각의 성별과 연 령에 따른 $\mathrm{BMI}$ 의 표준화점수( $\mathrm{z}$-score)를 구하였다. ${ }^{19} \mathrm{BMI}$ 가 연령 및 성별 95 백분위수 이상인 경우 비만으로, 5 백분위수 이하인 경우 저성장으로 판정하였다. ${ }^{19}$

\section{수면다원검사 및 폐쇄성 무호흡-저호흡 지수(obstructive apnea-hypopnea index)}

수면다원검사는 표준뇌파(C3-A2, C4-A1, F3-A2, F4$\mathrm{A} 1, \mathrm{O} 1-\mathrm{A} 2, \mathrm{O} 2-\mathrm{A} 1)$, 안전도(ROC-A1, $\mathrm{LOC}-\mathrm{A} 2$, 근전도 (electromyography), 심전도, 산소포화도(pulse oximetry), 그리고 코골이 측정을 위한 목 마이크 등을 사용하여 시행하 였다. 근전도는 턱밑근(submental muscle)과 양측 앞정강근 (tibialis anterior muscle)에서 기록하였다. 호흡량 측정을 위 해서는 입코열전대(oronasal thermistor)와 코압력변환기 (nasal pressure transducer)를, 호흡노력을 측정하기 위해서
는 흥곽과 복부에 교류저항 체적 변동기록법(plethysmography)을 사용하였다. 수면단계 및 그와 연관된 사건은 미국수 면학회의 규정집(the American Academy of Sleep Medicine manual for the scoring of sleep and associated events v2.0) 에 근거해서 판독하였다. ${ }^{20}$ 무호흡은 호흡량 진폭이 $90 \%$ 이 상 감소를 보이면서 기준 호흡수의 2개 이상 지속되는 것으 로 정의하였다. 저호흡은 호흡량 진폭이 $30 \%$ 이상 감소가 기준 호흡수의 2 개 이상 지속되면서 뇌파에서 미세 각성 또 는 산소포화도가 $3 \%$ 이상 감소되는 것으로 정의하였다. 폐 쇄성 무호흡-저호흡 지수(obstructive apnea-hypopnea index, $\mathrm{OAHI}$ 는 시간당 폐쇄성 및 복합성 무호흡과 저호흡이 나타나 는 빈도수로 정의하였다. 기존 보고 ${ }^{1}$ 및 선행 연구 ${ }^{17}$ 를 참고하 여, 정상은 $\mathrm{OAHI}<1$, 경증 $\mathrm{OSAS}$ 는 $1 \leq \mathrm{OAHI}<5$, 그리고 중등 도/중증 OSAS는 $\mathrm{OAHI} \geq 5$ 로 정의하였다.

\section{혈액 표지자}

의무기록에서 $\mathrm{CBC}$ 검사 결과상의 혈색소(hemoglobin, $\mathrm{Hb}), \mathrm{RDW}, \mathrm{MPV}$, 혈소판(platelet, PLT), 혈소판크기분포폭 (platelet distribution width, PDW)과 백혈구(white blood cell, WBC) 수, 중성구(neutrophil) 수와 림프구(lymphocyte) 수를 조사했으며 이를 바탕으로 NLR과 PLR을 계산하였다. 채혈은 야간 금식 후 아침에 정맥을 통해 이루어졌으며, PSG 검사 전후 1 개월 내에 검사가 이루어진 경우만 대상군으로 포함했다.

\section{통계 분석}

대상군을 $\mathrm{OAHI}$ 값에 따라 정상 $(\mathrm{OAHI}<1)$ 군, 경증 $\mathrm{OSAS}(1 \leq$ $\mathrm{OAHI}<5)$ 군과 중등도/중증 $\mathrm{OSAS}(\mathrm{oAHI} \geq 5)$ 군의 세 그룹으 로 나누었다. 이 세 그룹 간의 BMI z-score, 성별, 연령, 혈액 표지자들 $(\mathrm{Hb}, \mathrm{RDW}, \mathrm{MPV}, \mathrm{PLT}, \mathrm{PDW}, \mathrm{WBC}, \mathrm{NLR}, \mathrm{PLT})$ 의 통계적 차이를 분석했다. 연속형 변수들은 일표본 Kolmogorov-Smirnov 검정을 사용하여 정규분포 여부를 분석 하고, 정규분포를 따르는 경우는 대표값을 평균 \pm 표준편차 로 표시하고 정규분포를 따르지 않는 경우는 대표값을 중위 수(사분위수 범위, interquartile range)로 표시했다. 정규분포 를 따르는 연속형 변수들의 분석에는 독립 일원배치분산 분 석(one-way ANOVA) 후 Tukey 사후 검정(post hoc analysis)을 시행했으며, 정규분포를 따르지 않는 연속형 변수들의 분석에는 Kruskal-Wallis 검정 후 각 그룹 간의 Mann-Whitney 검정 결과를 Bonferroni 방법으로 보정하여 사후 검정을 했다. 범주형 자료들의 분석에는 카이제곱 검정을 사용했다.

중등도/중증 OSAS 예측 모델을 만들기 위하여 $\mathrm{BMI}$ 의 zscore와 성별, 연령, 혈액 표지자들( $\mathrm{Hb}, \mathrm{RDW}, \mathrm{MPV}, \mathrm{PLT}$, 
$\mathrm{PDW}, \mathrm{WBC}, \mathrm{NLR}, \mathrm{PLT})$ 을 독립변수로 하고 정상군, 경증 $\mathrm{OSAS}$, 중등도/중증 OSAS군 해당 여부를 종속변수로 하여 다항 로지스틱 회귀분석(multinomial logistic regression analysis)을 실시하였다. 변수들 간의 상호작용을 보정하기 위하 여, 단변량(univariate) 분석에서 유의한 결과를 보인 독립변 수들을 선택하여 다변량(multivariate) 분석을 시행하였다. 통계분석에는 SPSS 14.0K for Windows(SPSS Inc., Chicago, $\mathrm{IL}, \mathrm{USA}$ )를 이용하였으며 $p$-value가 0.05 미만인 경우 통계 적으로 유의하다고 판정하였다.

\section{결 과}

\section{인구통계학적 특성}

정상, 경증 OSAS, 중등도/중증 OSAS 세 그룹 간에 연령, 성별과 $\mathrm{BMI}$ z-score는 통계적으로 유의한 차이를 보이지 않 았다(Table 1).

\section{혈액 표지자}

$\mathrm{RDW}, \mathrm{PDW}, \mathrm{WBC}$ 는 정상, 경증 $\mathrm{OSAS}$, 중등도/중증 OSAS 세 그룹 간에 통계적으로 유의한 차이를 보였다. 사후 검정에서 $\mathrm{RDW}$ 는 경증 $\mathrm{OSAS}$ 군과 중등도/중증 $\mathrm{OSAS}$ 군 간 에 차이를 보였으며, PDW는 정상군과 경증 OSAS군 사이에 서 차이를 보였다. $\mathrm{WBC}$ 는 정상군과 중등도/중증 $\mathrm{OSAS}$ 군 사이에서 차이를 보였다. $\mathrm{Hb}, \mathrm{PLT}, \mathrm{MPV}, \mathrm{NLR}$ 과 PLR은 세 그룹 간에 통계적으로 유의한 차이를 보이지 않았다(Table 1).

\section{중증도/중증 폐쇄수면무호흡 예측 모델}

단변량 다항 로지스틱 회귀분석 모델에서, RDW는 중등 도/중증 OSAS군과 경증 OSAS군 사이[odds ratio(OR) 7.08, 95\% confidence interval(CI) 1.78-39.22]와 중등도 OSAS군 과 정상군 사이 $(\mathrm{OR} 0.19,95 \% \mathrm{CI}$ 0.04-0.86)에서 유의한 차 이를 보였다. PDW는 경증 OSAS군과 정상군 사이(OR 1.05, 95\% CI 1.01-1.09)에서 유의한 차이를 보였으며, $\mathrm{WBC}$ 는 중

Table 1. Demographic, clinical, and hematologic characteristics of each group

\begin{tabular}{|c|c|c|c|c|}
\hline & \multicolumn{3}{|c|}{ oAHI } & \multirow{2}{*}{$p$-value } \\
\hline & $\mathrm{oAHI}<1 \quad(\mathrm{n}=18)$ & $1 \leq \mathrm{oAHI}<5(\mathrm{n}=26)$ & $\mathrm{oAHI} \geq 5(\mathrm{n}=13)$ & \\
\hline \multicolumn{5}{|l|}{ Age, years } \\
\hline mean $\pm S D$ & $8.16 \pm 2.91$ & $8.22 \pm 3.42$ & $7.26 \pm 3.50$ & $0.67^{*}$ \\
\hline \multicolumn{5}{|l|}{ Gender, male } \\
\hline$\%(\mathrm{n})$ & $55.6(10)$ & $69.2(18)$ & $53.8(7)$ & $0.54^{\dagger}$ \\
\hline \multicolumn{5}{|l|}{ BMI z-score } \\
\hline mean $\pm S D$ & $0.101 \pm 0.625$ & $0.052 \pm 0.889$ & $0.172 \pm 0.900$ & $0.91^{*}$ \\
\hline \multicolumn{5}{|l|}{$\mathrm{Hb}, 10^{3} / \mathrm{mL}$} \\
\hline mean \pm SD & $12.97 \pm 0.99$ & $12.86 \pm 1.07$ & $13.32 \pm 1.33$ & $0.47^{*}$ \\
\hline \multicolumn{5}{|l|}{ RDW } \\
\hline mean \pm SD & $12.78 \pm 0.49$ & $12.45 \pm 0.49 \S$ & $12.83 \pm 0.31^{\S}$ & $0.02 *$ \\
\hline \multicolumn{5}{|l|}{ PLT, $10^{3} / \mathrm{mL}$} \\
\hline mean \pm SD & $304.67 \pm 80.48$ & $333.27 \pm 80.71$ & $296.69 \pm 50.64$ & $0.27^{*}$ \\
\hline \multicolumn{5}{|l|}{ MPV } \\
\hline median (IQR) & $9.50(1.98)$ & $8.50(2.35)$ & $8.90(2.20)$ & $0.52^{\ddagger}$ \\
\hline \multicolumn{5}{|l|}{ PDW } \\
\hline median (IQR) & $11.05(10.12)^{\|}$ & $39.25(34.63)^{\|}$ & $13.30(35.95)$ & $0.04^{\ddagger}$ \\
\hline \multicolumn{5}{|l|}{$\mathrm{WBC}, 10^{3} / \mathrm{mL}$} \\
\hline mean \pm SD & $7.49 \pm 1.88^{\S}$ & $7.96 \pm 2.78$ & $9.87 \pm 3.30^{\S}$ & $<0.05^{*}$ \\
\hline \multicolumn{5}{|l|}{ NLR } \\
\hline median (IQR) & $0.83(0.49)$ & $0.97(0.43)$ & $1.04(1.42)$ & $0.78^{\ddagger}$ \\
\hline \multicolumn{5}{|l|}{ PLR } \\
\hline mean $\pm S D$ & $102.99 \pm 45.59$ & $106.42 \pm 39.22$ & $91.76 \pm 49.33$ & $0.61^{*}$ \\
\hline
\end{tabular}

${ }^{*}$ one-way ANOVA test, ${ }^{\dagger}$ chi-square test, ${ }^{\ddagger}$ Kruskal-Wallis test, ${ }^{\S}<0.05$ in Tukey post hoc test, ${ }^{\|}<0.05$ in Wilcoxon-Mann-Whitney test followed by manual adjustment for $p$-value by Bonferroni method. oAHI: obstructive apnea-hypopnea index, BMI: body mass index, Hb: hemoglobin, RDW: red blood cell distribution width, PLT: platelet, MPV: mean platelet volume, PDW: platelet distribution width, WBC: white blood cell, NLR: neutrophil/lymphocyte ratio, PLR: platelet/lymphocyte ratio, SD: standard deviation, IQR: interquartile range 
등도/중증 OSAS군과 정상군 사이(OR 1.39, 95\% CI 1.031.87)에서 유의한 차이를 보였다(Table 2).

단변량 다항 로지스틱 회귀분석 모델에서 유의한 차이를 보인 $\mathrm{RDW}, \mathrm{PDW}$ 와 $\mathrm{WBC}$ 를 이용한 다변량 다항 로지스틱 회귀 모델에서, RDW는 중등도/중증 OSAS군과 경증 OSAS 군 사이(adjusted OR 8.77, 95\% CI 1.28-60.22)에서 유의한 차이를 보였다. PDW는 경증 OSAS군과 정상군 사이(adjusted OR 1.05, 95\% CI 1.00-1.09)에서 WBC는 중등도/중증 OSAS군과 정상군 사이(adjusted OR 1.42, 95\% CI 1.031.94)에서 차이를 보였다(Table 3). 다변량 다항 로지스틱 회 귀분석 모델은 전체 변화량의 $33 \%$ 를 설명할 수 있는 것으로 나타났다(pseudo $\mathrm{R}^{2}=0.33$ ).

\section{고 찰}

OSAS가 일종의 면역 조절곤란(dysregulation)을 일으켜 서, 염증 반응을 활성화시키고 전파시킴은 잘 알려져 있 다. ${ }^{21,22}$ 소아와 청소년에서도 역시 OSAS에 의한 여러 염증 매 개체(mediators)의 증가와 IL-6 같은 항염증 물질의 감소가
보고되어 있다. ${ }^{23-25}$ 결국 OSAS를 가진 소아청소년은 낮은 정도의 만성 염증(chronic, low-grade inflammation) 상태임 을 알 수 있다. ${ }^{22}$

최근 성인에서는 비용이 저렴하고 이미 널리 사용하고 있 는 $\mathrm{CBC}$ 에 포함된 $\mathrm{RDW}, \mathrm{PDW}, \mathrm{MPV}$ 등의 지표들을 이용한 OSAS 선별 진단에 대한 연구들이 많이 이루어졌다. ${ }^{8-16}$ 이 중 소아 및 청소년 대상의 기존 연구 ${ }^{17}$ 와 본 연구에서 공통되 게 유용성을 보여준 것은 RDW이다. RDW는 인구 집단 코 호트 연구에서 불량한 예후(adverse outcome)의 예측인자로 도 주목받고 있으며, 특히 심근 경색 환자에서 심혈관계 이환 율 및 사망률과도 관계가 있는 것으로 믿어지고 있다. ${ }^{26-29}$ 또 한 중환자실 환자의 불량한 예후를 예측하는 인자로도 유용 성이 있음이 보고되고 있다. ${ }^{30,31}$

$\mathrm{RDW}$ 는 적혈구(red blood cell, $\mathrm{RBC}$ ) 크기의 다양성(variability)을 나타내는 측정치로 기본 $\mathrm{CBC}$ 결과에 포함되며, 저색소 소적혈구 빈혈(hypochromic microcytic anemia)의 감별 진단에 쓰인다. ${ }^{16,32} \mathrm{RBC}$ 의 표준 크기(standard size)는 약 6 8 $\mu \mathrm{m}$ 이며, RDW의 정상 범위는 11 15\%이다. ${ }^{32,33}$ 적혈 구 크기의 이상(derangements)은 적혈구 형태에 영향을 주거

Table 2. Estimated crude OR from the univariate multinomial logistic regression model to predict moderate to severe obstructive sleep apnea syndrome

\begin{tabular}{|c|c|c|c|}
\hline & oAHI $\geq 5$ (Ref. oAHI $<1$ ) & oAHI $\geq 5$ (Ref. $1 \leq \mathrm{oAHI}<5)$ & $1 \leq \mathrm{oAHI}<5($ Ref. oAHI $<1)$ \\
\hline & OR $(95 \% \mathrm{CI})$ & OR $(95 \% \mathrm{CI})$ & OR $(95 \% \mathrm{CI})$ \\
\hline Age, years & $0.91(0.72-1.15)$ & $0.91(0.73-1.13)$ & $1.01(0.84-1.21)$ \\
\hline Gender, male & $0.93(0.22-3.85)$ & $0.52(0.13-2.04)$ & $1.79(0.51-6.25)$ \\
\hline BMI z-score & $1.12(0.46-2.72)$ & $1.21(0.53-2.78)$ & $0.93(0.43-1.97)$ \\
\hline $\mathrm{Hb}, 10^{3} / \mathrm{mL}$ & $1.31(0.70-2.46)$ & $1.45(0.80-2.64)$ & $0.90(0.51-1.61)$ \\
\hline RDW & $1.31(0.26-6.54)$ & $7.08(1.78-39.22)^{*}$ & $0.19(0.04-0.86)^{*}$ \\
\hline PLT, $10^{3} / \mathrm{mL}$ & $1.00(0.99-1.01)$ & $0.99(0.98-1.00)$ & $1.01(1.00-1.01)$ \\
\hline MPV & $0.89(0.54-1.48)$ & $1.05(0.65-1.70)$ & $0.85(0.56-1.31)$ \\
\hline PDW & $1.04(0.99-1.09)$ & $0.99(0.95-1.03)$ & $1.05(1.01-1.09)^{*}$ \\
\hline $\mathrm{WBC}, 10^{3} / \mathrm{mL}$ & $1.39(1.03-1.87)^{*}$ & $1.27(0.99-1.65)$ & $1.09(0.84-1.41)$ \\
\hline NLR & $1.13(0.77-1.67)$ & $1.33(0.82-2.17)$ & $0.85(0.51-1.42)$ \\
\hline PLR & $0.99(0.98-1.01)$ & $0.99(0.97-1.01)$ & $1.00(0.99-1.02)$ \\
\hline
\end{tabular}

${ }^{*} p$-value<0.05. OR: odds ratio, oAHI: obstructive apnea-hypopnea index, Ref.: reference, CI: confidence interval, BMI: body mass index, Hb: hemoglobin, RDW: red blood cell distribution width, PLT: platelet, MPV: mean platelet volume, PDW: platelet distribution width, WBC: white blood cell, NLR: neutrophil/lymphocyte ratio, PLR: platelet/lymphocyte ratio

Table 3. Estimated adjusted OR from the multivariate multinomial logistic regression model to predict moderate to severe obstructive sleep apnea syndrome

\begin{tabular}{|c|c|c|c|}
\hline & oAHI $\geq 5$ (Ref. oAHI<1) & oAHI $\geq 5($ Ref. $1 \leq \mathrm{oAHI}<5)$ & $1 \leq \mathrm{oAHI}<5($ Ref. oAHI $<1)$ \\
\hline & OR (95\% CI) & OR (95\% CI) & OR (95\% CI) \\
\hline RDW & $2.08(0.33-13.25)$ & $8.77(1.28-60.22)^{*}$ & $0.24(0.05-1.12)$ \\
\hline PDW & $1.04(0.99-1.09)$ & $0.99(0.95-1.04)$ & $1.05(1.00-1.09)^{*}$ \\
\hline WBC, $10^{3} / \mathrm{mL}$ & $1.42(1.03-1.94)^{*}$ & $1.26(0.97-1.64)$ & $1.12(0.84-1.50)$ \\
\hline
\end{tabular}

${ }^{*} p$-value<0.05. Pseudo $\mathrm{R}^{2}=0.33$. oAHI: obstructive apnea-hypopnea index, Ref.: reference, OR: odds ratio, CI: confidence interval, RDW: red blood cell distribution width, PDW: platelet distribution width, WBC: white blood cell 
나 미성숙 망상적혈구(premature reticulocyte)의 방출을 초 래하는 어떠한 생리적 현상에 의해서도 초래될 수 있다. 30,31 염증 전구 시토카인(proinflammatory cytokines)은 RBC의 생존을 저해하면서 동시에 $\mathrm{RBC}$ 막을 변형시키는 것으로 생 각된다. ${ }^{31}$ 그 결과 적혈구(erythrocyte)의 성숙이 방해받고, 망상적혈구증의 상향조절(upregulation)이 초래되어 크고 미 성숙한 망상적혈구(large naive reticulocyte)가 방출되면서 $\mathrm{RDW}$ 가 증가된다. ${ }^{34}$ 또한 $\mathrm{RBC}$ 생성은 생리적인 스트레스 기간 동안 스트레스 적혈구생성(stress erythropoiesis)에 의 해서도 상승될 수 있다. 35,36 이러한 과정의 주된 매개체는 저 산소증(hypoxia), 줄기세포인자(stem cell factor, $\mathrm{SCF}$ )와 같 은 스트레스-유도 인자들(stress-induced factors)과 글루코 코르티코이드(glucocorticoid)이다. 35,37 저산소증 노출과 급성 스트레스에 의한 글루코코르티코이드의 분비 증가는 적혈구 형성인자(erythropoietin) 수용체를 자극하여 RBC 생성을 증가시킨다. ${ }^{37,38}$ 또한 글루코코르티코이드는 $\mathrm{SCF}$ 를 위한 수 용체인 c-kit와 반응하여 직접적으로 적혈구 전구세포(erythroid progenitor)의 분화를 약화시킨다. ${ }^{37}$ 이러한 분화의 지 연은 미성숙 $\mathrm{RBC}$ 의 지속적인 성장을 가져와 $\mathrm{RDW}$ 증가에 일조를 하게 된다. ${ }^{30}$ 이러한 기전에 의해 중등도/중증 OSAS 소아와 청소년의 RDW의 상승을 설명할 수 있을 것이다.

$\mathrm{PDW}$ 는 MPV와 함께 혈소판의 활성화를 반영하여 증가하 며, 활성화 초기에 MPV보다 먼저 변화하는 것으로 알려져 있다. ${ }^{25}$ 혈소판은 면역 조절자(modulator) 및 효과기(effector) 로 염증 반응에 깊이 관여한다. ${ }^{39} \mathrm{OSAS}$ 에 의한 만성 염증 반 응에 의해 이러한 PDW의 증가가 보임을 생각할 수 있으며, 성인 OSAS 연구들에서도 본 연구와 비슷한 결과들을 보여 주었다. ${ }^{911}$ 본 연구와 Erdim 등의 소아청소년 대상의 연구에 서는 공통적으로 성인 연구들에서 강조되었던 MPV의 유의 한 증가가 관찰되지 않았다. ${ }^{8-10,17}$ 이는 소아청소년 OSAS 환 자와 성인 OSAS 환자 간의 비만율의 차이 및 저산소 노출량 (hypoxic dose) 차이에 의해서 나타나는 현상으로 생각된다. Choi 등의 연구는 소아청소년 OSAS 환자는 성인 OSAS 환 자와 비교하여 산소포화도의 저하 및 apnea-hypopnea index (AHI)가 낮으며 비만율도 낮은 것으로 보고하였다. ${ }^{40}$ 이러한 소아청소년과 성인의 차이가 본 연구 및 $\mathrm{Erdim}$ 등의 연구와 기존 성인 연구들의 차이를 가져왔을 것으로 생각할 수 있 다. ${ }^{8-10,17}$ 하지만 본 연구와 같이 정상 체중 소아를 대상으로 한 Zicari 등의 연구에서는 단순 코골이군[primary snoring (PS), $\mathrm{AHI}<1$ ]과 $\mathrm{OSAS}$ 군 $(\mathrm{AHI} \geq 1)$ 사이에서는 $\mathrm{MPV}$ 의 유 의한 차이가 보이지 않았지만, ${ }^{18}$ 습관적 코골이 및 비염의 병 력이 없는 정상군과 비교해서는 PS군과 OSAS군 모두 MPV 수치의 증가가 관찰되었다고 보고하였다. 이는 본 연구의 대
상군이 대부분 수면무호흡증의 감별 진단을 위해 $\mathrm{PSG}$ 를 시행 했다는 사실에 기반해서 추론하면, 선택 편향(selection bias)에 의한 결과일 가능성도 완전히 차치할 수는 없을 것이다.

흥미로운 것은 소아청소년의 아데노이드 절제술 전/후 $\mathrm{MPV}$ 를 비교한 한 연구에서 수술 후, 통계적으로 유의하지 는 않았지만, MPV의 증가가 보고된 것이다. ${ }^{41}$ 이는 비만아와 정상 체중아 모두 아데노이드 절제술 후 체중 증가를 보인다 는 보고들과 MPV가 비만군에서는 BMI와 상관관계를 보였 지만, ${ }^{1}$ 정상 체중군에서는 이러한 상관관계가 확인되지 않았 다는 보고를 종합하여 고려하면 비만이라는 혼란 변수에 의 해 설명 가능한 현상이라고 생각된다. ${ }^{42}$ 이후 다른 연구에서 소아청소년에서 아데노이드 절제술 후 MPV 감소가 보임을 보고한 것은 이에 대한 방증이 될 수 있을 것이다. ${ }^{43}$ 하지만 상 기한 연구들에서 실험 대상군의 BMI나 체중을 제시하고 있지 않아서, 이를 확인하기 위해서는 후속 연구가 필요할 것으로 보인다. ${ }^{41,43}$

$7.26 \pm 3.50$ 세의 정상 체중 소아와 청소년을 대상으로 한 본 연구에서는 RDW, $\mathrm{WBC}, \mathrm{PDW}$ 가 중등도/중증 $\mathrm{OSAS}$ 군 에서 통계적으로 유의한 증가를 보여주었지만, NLR과 PLR 은 통계적으로 유의한 증가를 보이지 않았다. $11.71 \pm 1.38$ 세 의 비만아 83명을 대상으로 한 Erdim 등의 연구에서는 $\mathrm{RDW}$ 외에도 NLR과 PLR도 $\mathrm{AHI} \geq 5$ 군에서 유의하게 상승 해 있음을 보고했다..$^{17}$ 이러한 차이는 각 연구 대상군의 연령 및 비만 유무의 차이에서 기인할 수도 있다. 비만은 자체로 만성 염증의 원인이 될 수 있다. ${ }^{21}$ 또한 여러 연구에서는 BMI 와 RDW 간에 유의한 상관관계가 있음이 보고되었다. ${ }^{11,30}$ 또 비만은 철분 부족을 일으켜 여러 $\mathrm{CBC}$ 지표들에 직간접적으 로 영향을 줄 수 있다.4 연령 역시 여러 가지 $\mathrm{CBC}$ 지표들에 영향을 줄 수 있다. ${ }^{45}$ 물론 비교적 소규모 그룹을 대상으로 한 후향적 연구인 본 연구의 특성상 선택 편향(selection bias)이 발생했을 가능성도 역시 고려해야 할 것이다.

본 연구에서는 $\mathrm{RDW}, \mathrm{WBC}$ 와 $\mathrm{PDW}$ 가 정상 체중 소아청 소년에서도 중등도/중증 OSAS에 유용한 진단적 가치를 가 짐을 보여주었다. 특히 한 가지 표지자를 사용하는 것보다는 본 연구의 다변량 모델에서 보여준 것처럼, 여러 표지자들을 함께 사용한다면 진단적 가치를 배가할 수 있을 것으로 사료 된다. 본 연구는 단일기관의 후향적 단면 연구로, 결과의 해 석에는 여러 가지 편향에 대한 고려가 필요할 것으로 사료되 나, 이후 전향적 연구 및 대규모 연구의 근거 자료로서 쓰일 수 있기를 기대한다.

\section{REFERENCES}

1. Marcus CL, Brooks LJ, Draper KA, et al.; American Academy of Pediatrics. Diagnosis and management of childhood obstructive sleep ap- 
nea syndrome. Pediatrics 2012;130:e714-e755.

2. Horwood L, Brouillette RT, McGregor CD, Manoukian JJ, Constantin E. Testing for pediatric obstructive sleep apnea when health care resources are rationed. JAMA Otolaryngol Head Neck Surg 2014;140:616-623.

3. Carroll JL, McColley SA, Marcus CL, Curtis S, Loughlin GM. Inability of clinical history to distinguish primary snoring from obstructive sleep apnea syndrome in children. Chest 1995;108:610-618.

4. Constantin E, Tewfik TL, Brouillette RT. Can the OSA-18 quality-oflife questionnaire detect obstructive sleep apnea in children? Pediatrics 2010;125:e162-e168.

5. Brouillette RT, Morielli A, Leimanis A, Waters KA, Luciano R, Ducharme FM. Nocturnal pulse oximetry as an abbreviated testing modality for pediatric obstructive sleep apnea. Pediatrics 2000;105:405-412.

6. Kim SS, Yang KI. The utility of the McGill overnight oximetry score for the moderate to severe obstructive sleep apnea syndrome in Korean children. J Sleep Med 2016;13:15-20.

7. De Luca Canto G, Pachêco-Pereira C, Aydinoz S, Major PW, FloresMir C, Gozal D. Diagnostic capability of biological markers in assessment of obstructive sleep apnea: a systematic review and meta-analysis. J Clin Sleep Med 2015;11:27-36.

8. Sökücü SN, Ozdemir C, Dalar L, Karasulu L, Aydın S, Altın S. Is mean platelet volume really a severity marker for obstructive sleep apnea syndrome without comorbidities? Pulm Med 2014;2014:754839.

9. Nena E, Papanas N, Steiropoulos P, et al. Mean platelet volume and platelet distribution width in non-diabetic subjects with obstructive sleep apnoea syndrome: new indices of severity? Platelets 2012;23:447454.

10. Varol E, Ozturk O, Yucel H, et al. The effects of continuous positive airway pressure therapy on mean platelet volume in patients with obstructive sleep apnea. Platelets 2011;22:552-556.

11. Kurt OK, Yildiz N. The importance of laboratory parameters in patients with obstructive sleep apnea syndrome. Blood Coagul Fibrinolysis 2013;24:371-374.

12. Korkmaz M, Korkmaz H, Küçüker F, Ayyıldız SN, Çankaya S. Evaluation of the association of sleep apnea-related systemic inflammation with CRP, ESR, and neutrophil-to-lymphocyte ratio. Med Sci Monit 2015; 21:477-481.

13. Oyama J, Nagatomo D, Yoshioka G, et al. The relationship between neutrophil to lymphocyte ratio, endothelial function, and severity in patients with obstructive sleep apnea. J Cardiol 2016;67:295-302.

14. Yenigun A, Karamanli H. Investigation of the relationship between neutrophil-to-lymphocyte ratio and obstructive sleep apnoea syndrome. $J$ Laryngol Otol 2015;129:887-892.

15. Koseoglu HI, Altunkas F, Kanbay A, Doruk S, Etikan I, Demir O. Platelet-lymphocyte ratio is an independent predictor for cardiovascular disease in obstructive sleep apnea syndrome. J Thromb Thrombolysis 2015;39:179-185.

16. Sökücü SN, Karasulu L, Dalar L, Seyhan EC, Altın S. Can red blood cell distribution width predict severity of obstructive sleep apnea syndrome? J Clin Sleep Med 2012;8:521-525.

17. Erdim I, Erdur O, Oghan F, Mete F, Celik M. Blood count values and ratios for predicting sleep apnea in obese children. Int J Pediatr Otorhinolaryngol 2017;98:85-90.

18. Zicari AM, Occasi F, Di Mauro F, et al. Mean platelet volume, vitamin $\mathrm{D}$ and $\mathrm{C}$ reactive protein levels in normal weight children with primary snoring and obstructive sleep apnea syndrome. PLoS One 2016 Apr 7 [Epub ahead of print]. https://doi.org/10.1371/journal.pone.0152497.

19. Kim JH, Yun S, Hwang SS, et al.; Committee for the Development of Growth Standards for Korean Children and Adolescents; Committee for School Health and Public Health Statistics, the Korean Pediatric Society; Division of Health and Nutrition Survey, Korea Centers for Disease Control and Prevention. The 2017 Korean national growth charts for children and adolescents: development, improvement, and prospects. Korean J Pediatr 2018;61:135-149.

20. Berry RB, Brooks R, Gamaldo CE, et al. The AASM manual for the scor- ing of sleep and association events: rules, terminology and technical specifications, version 2.0. Darien: American Academy of Sleep Medicine, 2012.

21. Gileles-Hillel A, Alonso-Álvarez ML, Kheirandish-Gozal L, et al. Inflammatory markers and obstructive sleep apnea in obese children: the NANOS study. Mediators Inflamm 2014 Jun 1 [Epub ahead of print]. https://doi.org/10.1155/2014/605280.

22. Ryan S, Taylor CT, McNicholas WT. Systemic inflammation: a key factor in the pathogenesis of cardiovascular complications in obstructive sleep apnoea syndrome? Thorax 2009;64:631-636.

23. Tan HL, Gozal D, Wang Y, et al. Alterations in circulating T-cell lymphocyte populations in children with obstructive sleep apnea. Sleep 2013; 36:913-922.

24. Gozal D, Serpero LD, Sans Capdevila O, Kheirandish-Gozal L. Systemic inflammation in non-obese children with obstructive sleep apnea. Sleep Med 2008;9:254-259.

25. Vagdatli E, Gounari E, Lazaridou E, Katsibourlia E, Tsikopoulou F, Labrianou I. Platelet distribution width: a simple, practical and specific marker of activation of coagulation. Hippokratia 2010;14:28-32.

26. Felker GM, Allen LA, Pocock SJ, et al.; CHARM Investigators. Red cell distribution width as a novel prognostic marker in heart failure: data from the CHARM Program and the Duke Databank. J Am Coll Cardiol 2007;50:40-47.

27. Patel KV, Ferrucci L, Ershler WB, Longo DL, Guralnik JM. Red blood cell distribution width and the risk of death in middle-aged and older adults. Arch Intern Med 2009;169:515-523.

28. Perlstein TS, Weuve J, Pfeffer MA, Beckman JA. Red blood cell distribution width and mortality risk in a community-based prospective cohort. Arch Intern Med 2009;169:588-594.

29. Braun E, Domany E, Kenig Y, Mazor Y, Makhoul BF, Azzam ZS. Elevated red cell distribution width predicts poor outcome in young patients with community acquired pneumonia. Crit Care 2011;15:R194.

30. Otero TMN, Yeh DD, Bajwa EK, et al. Elevated red cell distribution width is associated with decreased ventilator-free days in critically ill patients. J Intensive Care Med 2018;33:241-247.

31. Wang F, Pan W, Pan S, Ge J, Wang S, Chen M. Red cell distribution width as a novel predictor of mortality in ICU patients. Ann Med 2011; 43:40-46.

32. Harrington AM, Ward PC, Kroft SH. Iron deficiency anemia, betathalassemia minor, and anemia of chronic disease: a morphologic reappraisal. Am J Clin Pathol 2008;129:466-471.

33. Romero Artaza J, Carbia CD, Ceballo MF, Díaz NB. [Red cell distribution width (RDW): its use in the characterization of microcytic and hypochromic anemias]. Medicina (B Aires) 1999;59:17-22.

34. Sadaka F, O'Brien J, Prakash S. Red cell distribution width and outcome in patients with septic shock. J Intensive Care Med 2013;28:307-313.

35. Paulson RF, Shi L, Wu DC. Stress erythropoiesis: new signals and new stress progenitor cells. Curr Opin Hematol 2011;18:139-145.

36. Broudy VC, Lin NL, Priestley GV, Nocka K, Wolf NS. Interaction of stem cell factor and its receptor c-kit mediates lodgment and acute expansion of hematopoietic cells in the murine spleen. Blood 1996;88:7581.

37. von Lindern M, Zauner W, Mellitzer G, et al. The glucocorticoid receptor cooperates with the erythropoietin receptor and c-Kit to enhance and sustain proliferation of erythroid progenitors in vitro. Blood 1999;94:550-559.

38. Bauer A, Tronche F, Wessely O, et al. The glucocorticoid receptor is required for stress erythropoiesis. Genes Dev 1999;13:2996-3002.

39. Jenne CN, Kubes P. Platelets in inflammation and infection. Platelets 2015;26:286-292.

40. Choi JH, Kim EJ, Choi J, et al. Obstructive sleep apnea syndrome: a child is not just a small adult. Ann Otol Rhinol Laryngol 2010;119:656661.

41. Onder S, Caypinar B, Sahin-Yilmaz A, Toros SZ, Oysu C. Relation of mean platelet volume with obstructive adenoid hypertrophy in chil- 
dren. Int J Pediatr Otorhinolaryngol 2014;78:1449-1451.

42. Coban E, Ozdogan M, Yazicioglu G, Akcit F. The mean platelet volume in patients with obesity. Int J Clin Pract 2005;59:981-982.

43. Soyalıç H, Somuk BT, Doğru S, Gürbüzler L, Göktaş G, Eyibilen A. Evaluation of mean platelet volume and its ratio over platelet count in children with obstructive sleep apnea syndrome. Kulak Burun Bogaz
Ihtis Derg 2015;25:16-21.

44. Sal E, Yenicesu I, Celik N, et al. Relationship between obesity and iron deficiency anemia: is there a role of hepcidin? Hematology 2018:1-7.

45. Wang GC, Li N, Niu C, et al. Establishment of complete blood count reference intervals for Chinese preschoolers. J Clin Lab Anal $2016 \mathrm{Nov}$ 15 [Epub ahead of print]. https://doi.org/10.1002/jcla.22095. 